\title{
A macromolecular $N$-bromosulphonamide as a heterogeneous oxidant in acidic media
}

\author{
Agnieszka Ciechanowska $^{1} \cdot$ Elżbieta Kociołek-Balawejder $^{1}$
}

Received: 3 December 2014/Revised: 16 November 2015/Accepted: 29 November 2015/

Published online: 17 December 2015

(C) The Author(s) 2015. This article is published with open access at Springerlink.com

\begin{abstract}
Styrene-divinylbenzene copolymer containing $\mathrm{N}$-bromosulphonamide groups as sodium salt, $[\mathrm{P}]-\mathrm{SO}_{2} \mathrm{NBrNa}$, can be viewed as a high molecular weight redox polymer mimicking its low molecular weight analogue: Bromamine-T. The stability of this copolymer in acidic media has not been studied in detail to date. This paper reports on studies of the reaction between the copolymer and aqueous $\mathrm{FeSO}_{4}$ solution conducted in a series of batch and column experiments. It was found that $\mathrm{pH}<3.0$ results in transition of active bromine from $-\mathrm{SO}_{2} \mathrm{NBr}^{-}$groups to the solution, followed by oxidation of $\mathrm{Fe}^{2+}$ ions to $\mathrm{Fe}^{3+}$ ions by elemental bromine. In reaction media of $\mathrm{pH}>3.0$, active bromine remains bound to the functional groups, facilitating application of this copolymer as an effective oxidant in column processes running in weakly acidic reaction media. Results of the present work provide evidence that $-\mathrm{SO}_{2} \mathrm{NBr}^{-}$functional groups of the copolymer can stably exist in acidic form which is in contrast to the behaviour of the low molecular weight analogue ( $N$-bromo- $p$-toluenesulphonic acid does not occur as a pure chemical compound).
\end{abstract}

Keywords Redox copolymer - Heterogeneous oxidant · Macromolecular . $\mathrm{N}$-bromosulphonamide $\cdot$ Active bromine $\cdot \mathrm{Fe}(\mathrm{II})$ oxidation

\section{Introduction}

Bromamine-T (BAT, sodium salt of $N$-bromo- $p$-toluenesulphonamide) is a low molecular weight organic compound with an oxidizing effect, often used in oxidation reactions of, among others, alcohols, aldehydes, ketones and amines

Agnieszka Ciechanowska

agnieszka.ciechanowska@ue.wroc.pl

1 Department of Industrial Chemistry, Wrocław University of Economics, ul. Komandorska 118/120, 53-345 Wrocław, Poland 
[1-5]. Contemporary studies using BAT mainly concern the examination of drugs oxidation mechanisms in biological systems (drugs used, for instance, in the treatment of allergies and diabetes) [6-11]. Also, research work is conducted on the possibility of obtaining aziridine compounds from olefins (used, among other things, in the production of pharmaceuticals and optically active compounds) using BAT as a source of nitrogen [12-15]. The researchers dedicate a lot of attention to explanation of the oxidation reaction mechanism in acidic media, because under these conditions many reactions occurred much more favourably than without the addition of an acid or in the presence of alkaline medium. Under such conditions BAT (Ar-SO ${ }_{2} \mathrm{NBrNa}$ ) transforms to $\mathrm{Ar}-\mathrm{SO}_{2} \mathrm{NBrH}$ (1), which is unstable and undergoes reactions (2) and (3), as follows [3]:

$$
\begin{gathered}
\mathrm{Ar}-\mathrm{SO}_{2} \mathrm{NBrNa}+\mathrm{H}_{3} \mathrm{O}^{+} \leftrightarrow \mathrm{Ar}-\mathrm{SO}_{2} \mathrm{NBrH}+\mathrm{H}_{2} \mathrm{O}+\mathrm{Na}^{+} \\
2 \mathrm{Ar}-\mathrm{SO}_{2} \mathrm{NBrH} \leftrightarrow \mathrm{Ar}-\mathrm{SO}_{2} \mathrm{NH}_{2}+\mathrm{Ar}-\mathrm{SO}_{2} \mathrm{NBr}_{2} \\
\mathrm{Ar}-\mathrm{SO}_{2} \mathrm{NBrH}+\mathrm{H}_{2} \mathrm{O} \leftrightarrow \mathrm{Ar}-\mathrm{SO}_{2} \mathrm{NH}_{2}+\mathrm{HOBr}
\end{gathered}
$$

Synthesis of high molecular weight, water-insoluble reagent containing functional groups of similar chemical composition and properties generates new possibilities for research in this field.

A macromolecular BAT analogue is a macroporous copolymer having a styrenedivinylbenzene skeleton containing $N$-bromosulphonamide functional groups in a sodium form $(\mathrm{R} / \mathrm{BrNa})$ :<smiles>C[14CH2]S(=O)(=O)[N-]Br</smiles>

BAT<smiles>O=S(=O)([In])[N-]Br</smiles>

$\mathrm{R} / \mathrm{BrNa}$

[P] stands for the copolymer styrene-divinylbenzene macroporous structure.

We have described previously a method to obtain this copolymer, through a chemical modification of a commercially available sulphonic cation exchanger having a macroporous structure [16]. The product has a physical form analogous to ion exchangers, and its functional groups attached to the crosslinked macroporous matrix demonstrate high reactivity. Up to now, we have used materials of this type as heterogeneous oxidants to remove from water admixtures that are reductants. $\mathrm{R} / \mathrm{BrNa}$ used in column processes allowed the removal, from water (through oxidation), of such burdensome or toxic admixtures as cyanides, thiocyanates, sulphides, and arsenites [17-20]. This copolymer was particularly useful for the oxidation reaction in basic media in which similar copolymers containing in their functional groups active chlorine atoms are poorly reactive or unstable $[19,21]$. Thus, in the experiments conducted to date, we have primarily used $\mathrm{R} / \mathrm{BrNa}$, because of its pronounced reactivity in basic media. Up to now the behaviour of $\mathrm{R} / \mathrm{BrNa}$ in acidic media has not been examined in detail. In our previous paper related to the removal of $\mathrm{SCN}^{-}$ions 
from solutions, it turned out that during the column process the $\mathrm{pH}$ value of media considerably decreased (down to a $\mathrm{pH}$ value of 1.7-1.8) and bromine separated from the bed, as a result of which the copolymer lost its oxidizing property [18]. This phenomenon can be observed visually by the disappearance of the yellowish colour of the copolymer and coloration of the effluent. This phenomenon has proved that at a certain, low $\mathrm{pH}$ value functional groups lose active bromine.

A question arises whether it is possible to use $\mathrm{R} / \mathrm{BrNa}$ in acidic media, and what is the allowable, in approximation, low $\mathrm{pH}$ value of this oxidant's operation. The recognition of the properties and durability of $\mathrm{R} / \mathrm{BrNa}$ in acidic media can broaden the scope of its application since it is precisely the low $\mathrm{pH}$ value that fosters many oxidation reactions. To answer this question, aqueous $\mathrm{FeSO}_{4}$ solutions were selected as a substrate in the series of experiments studying the $\mathrm{pH}$ dependence of the following reaction:

$$
[\mathrm{P}]-\mathrm{SO}_{2} \mathrm{NBrNa}+2 \mathrm{Fe}^{2+}+2 \mathrm{H}^{+} \rightarrow[\mathrm{P}]-\mathrm{SO}_{2} \mathrm{NH}_{2}+2 \mathrm{Fe}^{3+}+\mathrm{Na}^{+}+\mathrm{Br}^{-}
$$

The aim of the present research was to examine the effect of the $N$ bromosulphonamide copolymer in the solution of a reductant the reaction of which is acidic. The point was to assess how low the $\mathrm{pH}$ value can drop while the heterogeneous oxidant still maintains in its functional groups the atoms of bromine, this being of utmost importance in the oxidation processes using the dynamic regime. Heterogeneous oxidizing agent, that is, stable and water-insoluble reactants, fit for use in a column process, providing a high redox potential, demonstrating a high oxidizing capacity, stable in terms of chemistry (i.e., consuming the oxidizing capacity gradually, as the reductant solution is supplied onto the column) can be helpful in resolving many environmental problems resulting from the presence in various types of water in a microamount of toxic admixtures that are reductants.

\section{Experimental}

\section{Materials}

The heterogeneous oxidant used in this study, a crosslinked styrene-divinylbenzene copolymer with $\mathrm{N}$-bromosulphonamide groups $(\mathrm{R} / \mathrm{BrNa})$, was prepared by chemical modification of the commercially available cation exchanger Amberlyst 15 (Rohm and Haas Co.). Amberlyst 15 is a macroporous poly(S/20\%DVB) resin having $\mathrm{SO}_{3} \mathrm{H}$ groups $\left(4.70 \mathrm{mmol} \mathrm{g}{ }^{-1}\right.$ in the dry state); surface area $45 \mathrm{~m}^{2} \mathrm{~g}^{-1}$; average pore diameter $25 \mathrm{~nm}$. Sulphonic groups of the resin were transformed into $\mathrm{N}$ bromosulphonamide groups by a method published elsewhere [16]:

$$
\begin{array}{r}
{[\mathrm{P}]-\mathrm{SO}_{3} \mathrm{H} \stackrel{\mathrm{PCl}_{5} / \mathrm{POCl}_{3}}{\longrightarrow}[\mathrm{P}]-\mathrm{SO}_{2} \mathrm{Cl} \stackrel{\mathrm{NH}_{4} \mathrm{OH}}{\longrightarrow}[\mathrm{P}]-\mathrm{SO}_{2} \mathrm{NH}_{2}} \\
{[\mathrm{P}]-\mathrm{SO}_{2} \mathrm{NH}_{2} \stackrel{\mathrm{NaOCl}}{\longrightarrow}[\mathrm{P}]-\mathrm{SO}_{2} \mathrm{NClNa} \stackrel{\mathrm{NaBr}}{\longrightarrow}[\mathrm{P}]-\mathrm{SO}_{2} \mathrm{NBrNa}}
\end{array}
$$

The product contained $-\mathrm{SO}_{2} \mathrm{NBrNa}$ groups $1.64 \mathrm{mmol} \mathrm{g}^{-1}$ (i.e., 3.28 mequiv of active bromine $\mathrm{g}^{-1}$ ) and additionally $-\mathrm{SO}_{3} \mathrm{Na}$ groups $0.5 \mathrm{mmol} \mathrm{g}{ }^{-1}$. The presence 
of sulphonic groups in the $\mathrm{R} / \mathrm{BrNa}$ is a result of hydrolysis which occurs as a side reaction during the sulphonamide preparation.

Analytical grade ferrous sulphate (a reducing agent) was used for preparation of aqueous solutions. The solution used in the batch regime was $0.02 \mathrm{~mol} \mathrm{~L}^{-1} \mathrm{FeSO}_{4}$ $\left(1117 \mathrm{mg} \mathrm{Fe}^{2+} \mathrm{L}^{-1}\right)$ in deionized water. The solution used in the experiments carried out in the dynamic regime was $0.0025 \mathrm{~mol} \mathrm{~L}^{-1} \mathrm{FeSO}_{4}\left(139 \mathrm{mg} \mathrm{Fe}^{2+} \mathrm{L}^{-1}\right)$ in deionized water.

\section{Batch studies}

All experiments were carried out at room temperature. In the experiments involving the batch regime, samples of the resin $(0.61 \mathrm{~g}$ in the dry state, $1 \mathrm{mmol}$ of active bromine) were contacted with $0.02 \mathrm{~mol} \mathrm{~L}^{-1} \mathrm{FeSO}_{4}$ solution in a different volume (200, $50 \mathrm{~mL}$ ) ensuring a proper mole ratio-excess of ferrous ions or active bromine in relation to the stoichiometry of the reaction (4). Time-dependent measurements of $\mathrm{Fe}^{2+}$ and $\mathrm{Fe}^{3+}$ content in the solution were made. After $24 \mathrm{~h}$, the polymeric reagent was separated and the content of $\mathrm{Fe}^{2+}, \mathrm{Fe}^{3+}$, and $\mathrm{Br}^{-}$and $\mathrm{pH}$ was measured in the solution.

The redox titration of the resin was performed using $0.02 \mathrm{~mol} \mathrm{~L}^{-1} \mathrm{FeSO}_{4}$ solution. Eleven samples of the resin $(0.61 \mathrm{~g})$ were placed into separated vessels. Then the identified volumes of $\mathrm{FeSO}_{4}$ solution were introduced, which required bringing about, e.g., (5) $50 \%(50 \mathrm{~mL})$, (9) $100 \%(100 \mathrm{~mL})$ reduction of the active bromine present in the functional groups of the $\mathrm{R} / \mathrm{BrNa}$. To sample (1) only deionized water was added. The closed vessels were protected from light and from contact with air and shaken at constant, room temperature [22]. After $24 \mathrm{~h}$ in the solution the redox potential and $\mathrm{pH}$ were measured and the content of $\mathrm{Fe}^{2+}$ and $\mathrm{Fe}^{3+}$ was determined.

\section{Dynamic regime}

In the experiments involving the dynamic regime, a sample of the resin $(5.0 \mathrm{~g}$ in the dry state, $\sim 8.5 \mathrm{~mL}$ after swelling in water, $8.2 \mathrm{mmol}$ of active bromine) was packed into a glass column. An aqueous solution of $\mathrm{FeSO}_{4}\left(0.0025 \mathrm{~mol} \mathrm{~L}^{-1}\right)$ was passed through the resin bed. The flow rate was $29 \mathrm{BV} \mathrm{h}^{-1}$. The samples of the effluent $(250 \mathrm{~mL})$ were collected and analysed for the content of $\mathrm{Fe}^{2+}, \mathrm{Fe}^{3+}$, and $\mathrm{Br}^{-}$, and the $\mathrm{pH}$ was measured. After the process was finished (when the copolymer lost its oxidizing capacity) the resin bed was washed with $250 \mathrm{~mL}$ of $1 \mathrm{~mol} \mathrm{~L}^{-1}$ $\mathrm{H}_{2} \mathrm{SO}_{4}$, and the solution was analysed for the $\mathrm{Fe}^{2+}$ and $\mathrm{Fe}^{3+}$ content. Symbols used in the experiments: $C$ is the concentration of $\mathrm{Fe}^{2+}$ in the effluent, $V$ is the volume of effluent, $C / C_{0}$ is the changes in concentration of $\mathrm{Fe}^{2+}$ in the effluent, $V / V_{0}$ is the ratio of effluent volume to resin (bed) volume.

\section{Chemical analyses}

The active bromine in the copolymer was determined by the iodometric method. The ferrous and ferric ion concentrations were determined by standard 
spectrophotometric methods (Spekol 1200, Analytic Jena, Germany). The $\mathrm{Fe}^{2+}$ ions concentration was determined using the formation of an orange complex compound with 1,10-phenanthroline monohydrate. The absorbance measurement was taken at the wavelength $510 \mathrm{~nm}$. The $\mathrm{Fe}^{3+}$ ions concentration was determined using the formation of a red-coloured complex compound with potassium thiocyanate. The absorbance measurement was taken at the wavelength $480 \mathrm{~nm}$. The redox potential was measured by means of the platinum/calomel electrode pair, the $\mathrm{pH}$ values were tested by means of the glass/calomel electrode pair, and bromide ions were estimated by argentometric titration using $0.01 \mathrm{~mol} \mathrm{~L}^{-1} \mathrm{AgNO}_{3}$ with the $\mathrm{Ag} / \mathrm{AgCl} /$ calomel electrode system using a CPI-501 pH/ion meter, Elmetron, Poland.

\section{Results and discussion}

In the testing conducted using the batch regime solely a $0.02 \mathrm{~mol} \mathrm{\textrm {L } ^ { - 1 }}$ solution of $\mathrm{FeSO}_{4}$ in deionized water of $\mathrm{pH} 3.65$ was used. This $\mathrm{pH}$ was neither corrected downwards with addition of an acid (due to the said low and insignificant durability of $\mathrm{R} / \mathrm{BrNa}$ in acidic media), nor upwards with addition of a base (precipitation of $\mathrm{Fe}(\mathrm{OH})_{2}$ from the solution would follow).

At the first stage of the testing the oxidizing capacity of the R/BrNa copolymer in relation to $\mathrm{Fe}^{2+}$ was determined. To this aim, reductant $\left(\mathrm{FeSO}_{4}\right)$ was contacted in a ratio providing $100 \%$ of the reductant excess in relation to the amount resulting from the stoichiometry of the reaction (4). A sample of the $\mathrm{R} / \mathrm{BrNa}$ copolymer containing $1.0 \mathrm{mmol}$ of active bromine was treated with a $0.02 \mathrm{~mol} \mathrm{~L}^{-1} \mathrm{FeSO}_{4}$ solution containing $4 \mathrm{mmol}$ of $\mathrm{Fe}^{2+}$. During the course of the reaction the pale yellow solution turned yellow-orange. The characteristic smell of bromine was perceptible. It follows from the course of the curve presented in Fig. 1 that the oxidation reaction of $\mathrm{Fe}^{2+}$ ions occurred quickly; it was practically completed after $1 \mathrm{~h}$.

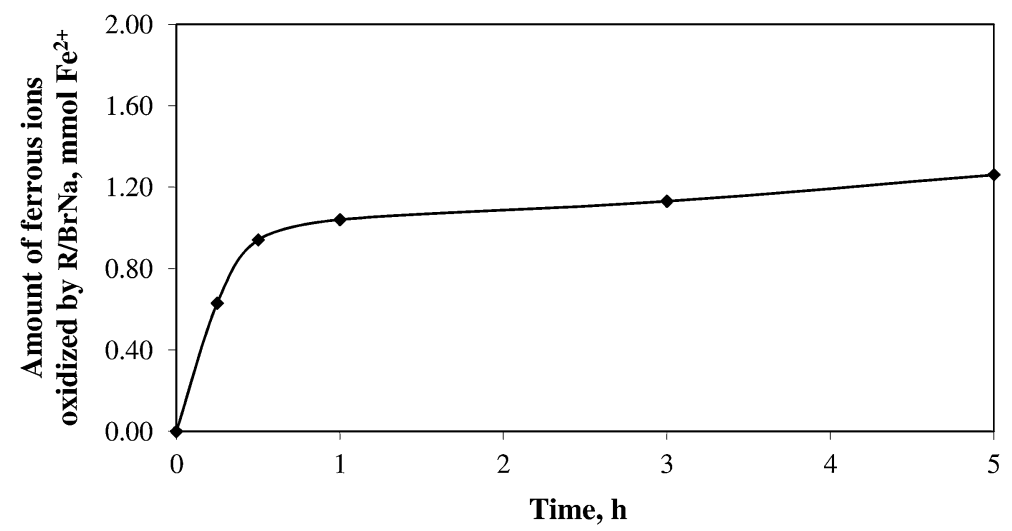

Fig. 1 Amount of ferrous ions oxidized by $N$-bromosulphonamide copolymer in solution in batch-wise reaction: $0.61 \mathrm{~g} \mathrm{R} / \mathrm{BrNa}+200 \mathrm{~mL} 0.02 \mathrm{~mol} \mathrm{~L}^{-1} \mathrm{FeSO}_{4}$ in water 
As follows from the data presented in Table 1, the reaction was accompanied by a drop of $\mathrm{pH}$, from 3.65 to 2.91. In the post-reaction solution $1 \mathrm{mmol} \mathrm{of} \mathrm{Br}^{-}$was detected, i.e., an amount consistent with the content of active bromine in the copolymer sample before the reaction. The fact of a change in the colour of the reaction solution, the rapid course of the reaction, as well as the absence of active halogen in the sample upon completion of the process, demonstrate that the reaction could have an autocatalytic course, caused by the drop in $\mathrm{pH}$. The change in the colour of the solution (which subsided after a certain time) evidenced that bromine separated from the copolymer that oxidized $\mathrm{Fe}^{2+}$ ions afterwards. During the reaction, the copolymer sample changed in colour from cream to brown. This was related to the separation of iron hydroxide within the copolymer structure:

$$
\begin{aligned}
{[\mathrm{P}]-\mathrm{SO}_{2} \mathrm{NBrNa}+2 \mathrm{FeSO}_{4}+6 \mathrm{H}_{2} \mathrm{O} \rightarrow[\mathrm{P}]-\mathrm{SO}_{2} \mathrm{NH}_{2} \# 2 \mathrm{Fe}(\mathrm{OH})_{3} } \\
+\mathrm{NaBr}+2 \mathrm{H}_{2} \mathrm{SO}_{4}
\end{aligned}
$$

\# means that $\mathrm{Fe}(\mathrm{OH})_{3}$ has been dispersed in the sulphonamide copolymer matrix.

Upon completion of the reaction, the sample was washed off with $1 \mathrm{~mol} \mathrm{~L}^{-1}$ $\mathrm{H}_{2} \mathrm{SO}_{4}$. It follows from the assessment of the balance of iron ions performed that the amount of $\mathrm{Fe}^{2+}$ ions oxidized in this process was $1.46 \mathrm{mmol}$, whereby a portion of $\mathrm{Fe}^{2+}$ ions was contained in the solution, whereas a part, as an $\mathrm{Fe}(\mathrm{OH})_{3}$ deposit, was contained in grains. Thus, this stage of the testing demonstrated that the drop in $\mathrm{pH}$ to 2.9 results in the separation of bromine into the solution.

At the next testing stage, reactants were used in a ratio to provide a $100 \%$ oxidant excess in relation to the stoichiometric amount.

Such proportions of reactants allowed us to verify whether complete removal of $\mathrm{Fe}^{2+}$ ions from the solution was possible. The copolymer sample, containing

Table 1 Results of 24-h batchwise reaction between $N$ bromosulphonamide copolymer (0.61 g, $1 \mathrm{mmol}$ active bromine) and ferrous ions $(200 \mathrm{~mL}$ $\left.0.02 \mathrm{~mol} \mathrm{~L}^{-1} \mathrm{FeSO}_{4}, 4 \mathrm{mmol}\right)$, a $100 \%$ excess of ferrous ions in relation to stoichiometry

\begin{tabular}{lc}
\hline Parameter & Value \\
\hline $\mathrm{Fe}^{2+}$ in solution, mmol & \\
Before reaction & 4.00 \\
After reaction & 2.54 \\
$\mathrm{Fe}^{3+}$ in solution, mmol & 0.87 \\
$\mathrm{After}^{3}$ reaction & \\
$\mathrm{Fe}^{\text {in sample of the resin, mmol }}$ & 0.02 \\
$\mathrm{Fe}^{2+}$ & 0.58 \\
$\mathrm{Fe}^{3+}$ & \\
$\mathrm{pH}$ & 3.65 \\
$\mathrm{Before}^{3+}$ & 2.91 \\
After reaction & \\
$\mathrm{Br}^{-}$in solution, mmol & 1.00 \\
After reaction & \\
Active bromine in sample of the resin, mmol & 1.00 \\
Before reaction & 0.00 \\
After reaction & \\
\hline
\end{tabular}


$1 \mathrm{mmol}$ of active bromine, was contacted with $0.02 \mathrm{~mol} \mathrm{~L}^{-1} \mathrm{FeSO}_{4}$ solution containing $1 \mathrm{mmol} \mathrm{Fe}^{2+}$. The results presented in Table 2 indicate that in the case under consideration a complete conversion of $\mathrm{Fe}^{2+}$ ions followed (no presence of them was found either in the post-reaction solution or in the copolymer). In the solution, the drop in $\mathrm{Fe}^{2+}$ ion concentration followed very quickly, which was not the case of an analogous reaction with the share of copolymers containing active chlorine [23]. The reaction was accompanied by a higher drop in $\mathrm{pH}$ than previously, to 2.66, and the copolymer sample changed colour from cream to brown due to the sedimentation of iron(III) hydroxides. As in the testing conducted with the reductant excess, at the beginning of the reaction, bromine passed through to the solution. In the copolymer sample analysed after the process, no presence of active bromine was found, although $50 \%$ of its initial amount should have remained in it. The test result evidenced the usefulness of $\mathrm{R} / \mathrm{BrNa}$ if the reaction is used in the processes of removal of residual amounts of $\mathrm{Fe}^{2+}$ from solutions under batch regime conditions.

At the next testing stage, the $\mathrm{R} / \mathrm{BrNa}$ copolymer was titrated potentiometrically using the $0.02 \mathrm{~mol} \mathrm{~L}^{-1} \mathrm{FeSO}_{4}$ solution. The testing aimed to determine how high was the redox potential that accompanied the oxidation reaction of $\mathrm{Fe}^{2+}$ ions using $\mathrm{R} / \mathrm{BrNa}$.

As follows from the course of the curves in Fig. 2, they differ significantly from the curves plotted under the same conditions for similar copolymers containing active chlorine [23]. The formal redox potential of the system (Fig. 2a) at measurement point 5 (50\% of reductant in relation to the stoichiometric amount resulting from Eq. (4) was $878 \mathrm{mV}$ at $\mathrm{pH}=2.77$, Fig. 2b). This value was significantly higher in comparison to the value of this parameter for reactions

Table 2 Results of 24-h batchwise reaction between $N$ bromosulphonamide copolymer (0.61 g, $1 \mathrm{mmol}$ active bromine) and ferrous ions $(50 \mathrm{~mL}$ $0.02 \mathrm{~mol} \mathrm{~L}^{-1} \mathrm{FeSO}_{4}, 1 \mathrm{mmol}$ ), a $100 \%$ excess of active bromine ions in relation to stoichiometry

\begin{tabular}{ll}
\hline Time, h & Characteristic of solution/resin \\
\hline & Concentration of $\mathrm{Fe}^{2+}$ in solution, $\mathrm{mg} \mathrm{L}^{-1}$ \\
0 & 1117 \\
1 & 246 \\
3 & 11 \\
5 & 0 \\
24 & 0 \\
& Concentration of Fe ${ }^{3+}$ in solution, $\mathrm{mg} \mathrm{L}^{-1}$ \\
24 & 628 \\
& Fe \\
24 & 23.84 \\
& pH \\
0 & 3.65 \\
24 & 2.66 \\
0 & Active bromine in sample of the resin, $\mathrm{mmol}^{3+}$ \\
24 & 1.00 \\
\hline
\end{tabular}



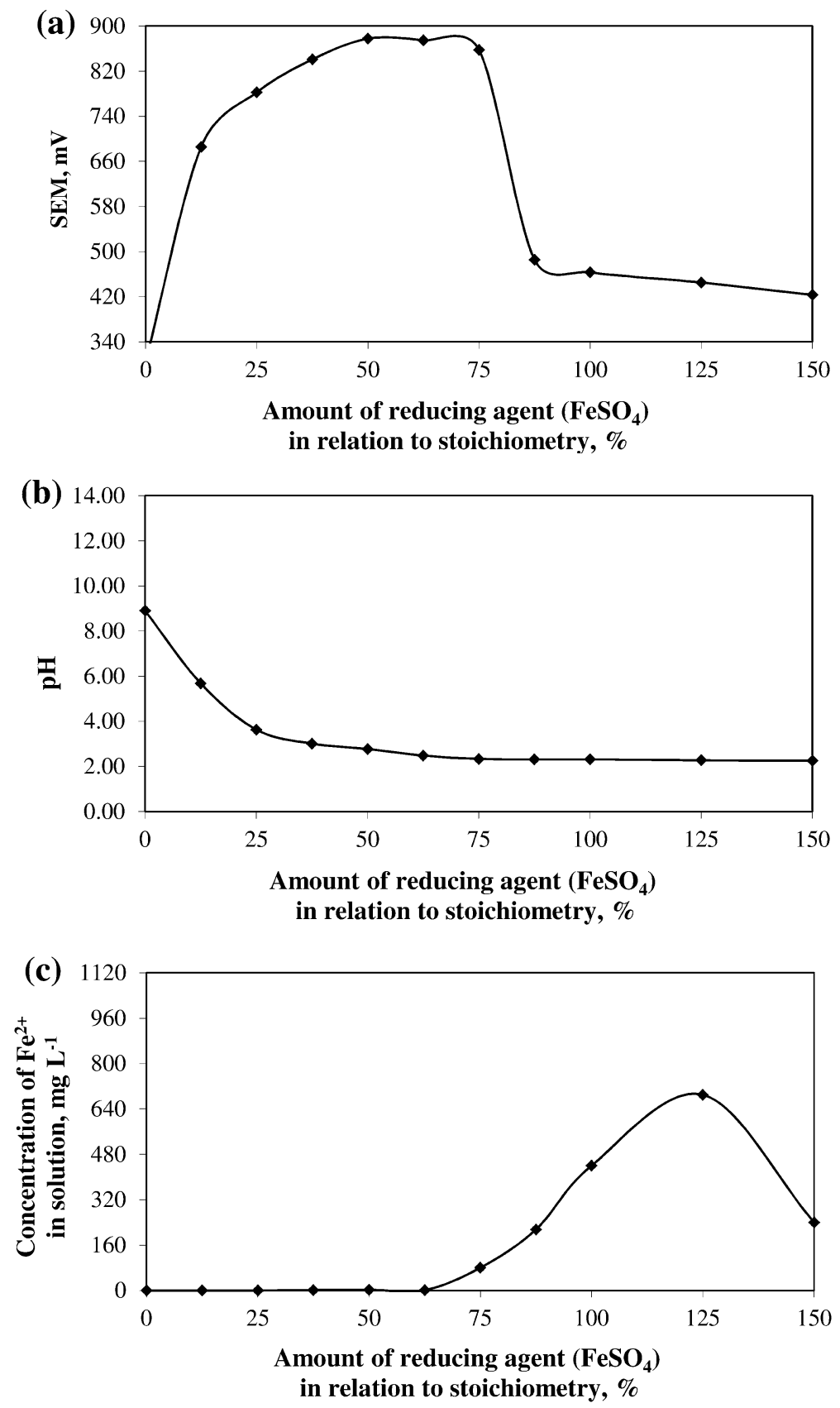

Fig. 2 a Redox titration curve of ferrous ions in solution during reaction of $N$-bromosulphonamide copolymer with $0.02 \mathrm{~mol} \mathrm{~L}^{-1} \mathrm{FeSO}_{4}, \mathbf{b} \mathrm{pH}$ value, $\mathbf{c}$ concentration of ferrous ions in solution 
conducted with the share of copolymers containing active chlorine [23]. Under the conditions described (measurement point 3 and the successive ones), $\mathrm{R} / \mathrm{BrNa}$ (being in excess) oxidized $\mathrm{Fe}^{2+}$ ions (Fig. 2c), and the "excessive part" of active bromine passed through to the solution, which was evidenced by a change in the colour of samples from cream to brown, a pungent smell of bromine, and a relatively low $\mathrm{pH}$ of the media (ca. 3.0 and lower starting with point 4). What is of interest, as can be seen in Fig. 2b, c, at the first two measurement points (sample 1 without addition of the reductant and a sample with addition of $12.5 \%$ of the reductant), the reaction progressed otherwise. It was accompanied by a rise in $\mathrm{pH}$ of the media, which is attributable to the partial hydrolysis of $-\mathrm{SO}_{2} \mathrm{NBrNa}$ groups and the appearance of $\mathrm{NaOBr}$ as a product of the reaction (similar to reaction (3)).

At the next testing stage, a bed of the $\mathrm{R} / \mathrm{BrNa}$ copolymer of a ca. $5.0 \mathrm{~g}$ mass was used, placed in a glass column. The bed contained ca. $8.2 \mathrm{mmol}$ of active bromine, and such an amount could oxidize $16.4 \mathrm{mmol}$ of $\mathrm{Fe}^{2+}$. As the influent, $0.0025 \mathrm{~mol}$ $\mathrm{L}^{-1} \mathrm{FeSO}_{4}$ solution with $\mathrm{pH}=3.61$ was used.

The results of the stationary testing showed that under the tested conditions until such a time that $\mathrm{pH}$ of the solution was within the range of 2.66-2.90, the oxidation of $\mathrm{Fe}^{2+}$ using $\mathrm{R} / \mathrm{BrNa}$ was accompanied by the separation to the solution of a higher amount of bromine than resulted from the stoichiometry of the reaction (4). Therefore, the course of the column process was particularly monitored, starting at the moment of its initiation (observation of the colour of the bed and monitoring of the smell of the solution).

As follows from the curves presented in Fig. 3a, the reaction of the $\mathrm{Fe}^{2+}$ oxidation progressed gradually, as the inflow was supplied onto the column, and the $\mathrm{pH}$ of the solution did not drop below 2.98 (Fig. 3b). It turned out that under these conditions active bromine remained bound with the copolymer. As follows from the course of the curve in Fig. 3a, c, in the first fractions of the effluent (up to $V / V_{0}$ $\sim 120$, ca. $1 \mathrm{~L}$ of effluent) no presence of either $\mathrm{Fe}^{2+}$ ions or $\mathrm{Fe}^{3+}$ ions was found. Until that moment, such an amount of the solution was passed through the column that contained ca. $2.5 \mathrm{mmol}$ of $\mathrm{Fe}^{2+}$ ions. $\mathrm{Fe}^{3+}$ ions formed as a result of the oxidation remained, at this stage, bound by sulphonic groups contained in the copolymer, and after the hydrolysis they settled partially in the bed in the form of $\mathrm{Fe}(\mathrm{OH})_{3}$ - a change in the bed colour from cream to brown was noted. The process was accompanied by a rise in the $\mathrm{pH}$ of the media. It should be added that during the column process, the maximum concentration of $\mathrm{Fe}^{3+}$ (Fig. 3c) in the effluent reached a value of $40.5 \mathrm{mg} \mathrm{L}^{-1}$, whereas a value of $139 \mathrm{mg} \mathrm{L}^{-1}$ was theoretically achievable.

The concentration of $\mathrm{Br}^{-}$ions, relatively high in the first fraction $(2.7 \mathrm{mmol}$ $\mathrm{L}^{-1}$ ), decreased to zero in the final fractions (upon passing $4.9 \mathrm{~L}, V / V_{0}=577$ of influent, Fig. 3d). It follows from the course of the curve that depicts the concentration of $\mathrm{Fe}^{3+}$ ions in the solutions received from the column that despite the completion of the $\mathrm{Fe}^{2+}$ oxidation reaction and with no presence of $\mathrm{Br}^{-}$ions in the effluent, minor amounts of $\mathrm{Fe}^{3+}$ are present in it $\left(<10 \mathrm{mg} \mathrm{L}^{-1}\right)$. This might have been caused by a partial washing out from the bed of previously precipitated iron compounds. The concentration of $\mathrm{Fe}^{2+}$ ions in the last fractions of the effluent was ca. $110 \mathrm{mg} \mathrm{L}^{-1}$ and was not proportional to that of $\mathrm{Fe}^{3+}$ ions (ca. $10 \mathrm{mg} \mathrm{L}^{-1}$ ). This 

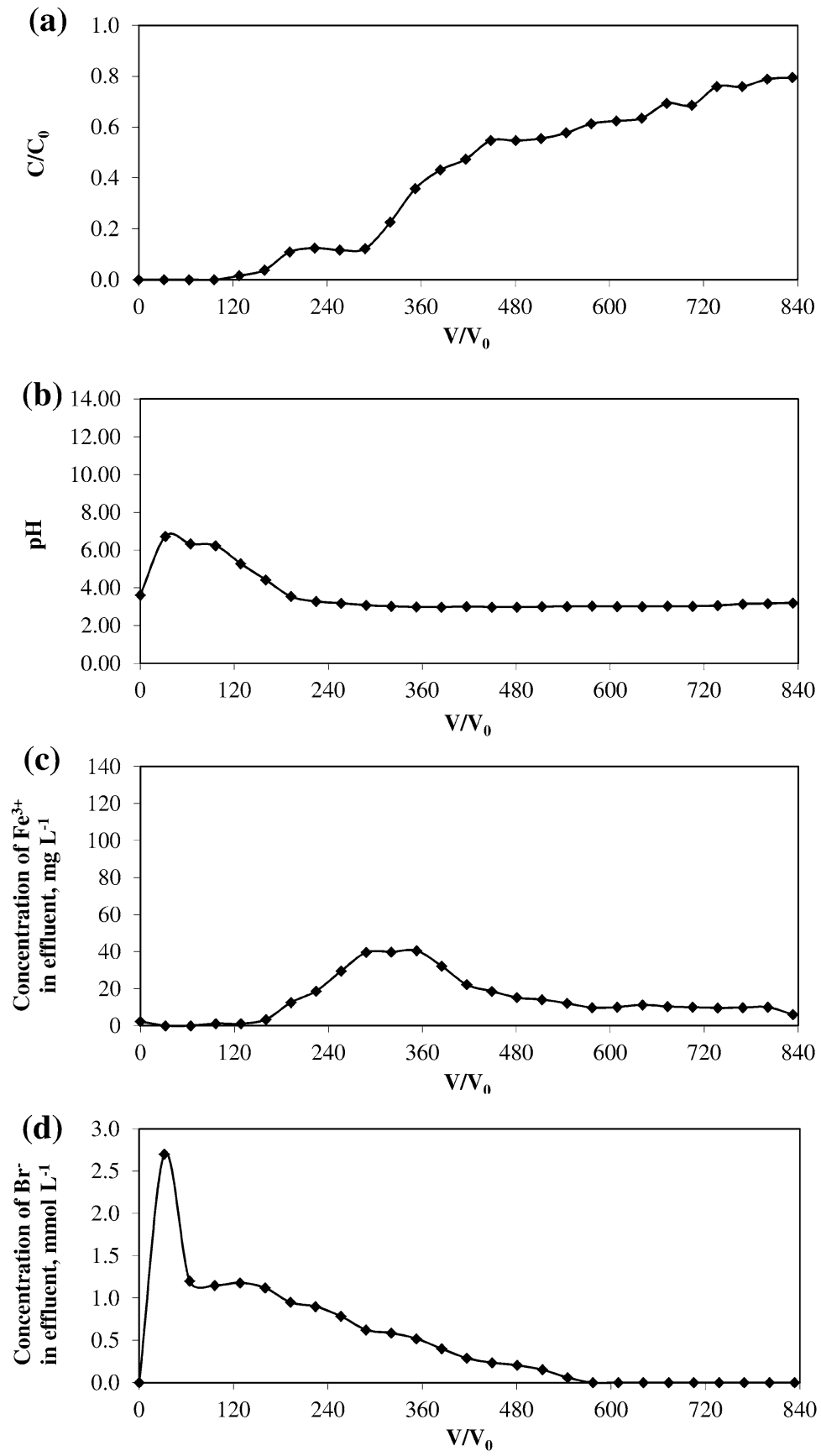

Fig. 3 a Ferrous ions breakthrough curve for $N$-bromosulphonamide copolymer in the column process: influx $0.0025 \mathrm{~mol} \mathrm{~L}^{-1} \mathrm{FeSO}_{4}$, flow rate $29 \mathrm{BV} \mathrm{h}^{-1}, \mathbf{b ~ p H}$ value, $\mathbf{c}$ concentration of ferric ions in effluent, d concentration of bromide ions in effluent 
could evidence the sorption of ions or hydroxides on the surface of previously precipitated iron compounds.

The process was completed upon passing ca. $7.1 \mathrm{~L}$ of the solution $\left(C / C_{0}=0.8\right.$, $V / V_{0}=840$ ), due to the fact that deposits precipitated in the bed caused problems with the flow of the solution through the column. Upon completion of the process, the bed was washed off with $1 \mathrm{~mol} \mathrm{~L}^{-1} \mathrm{H}_{2} \mathrm{SO}_{4}$. The analysis has demonstrated the contents in the solution of $1.40 \mathrm{mmol}$ of $\mathrm{Fe}^{2+}$ and $6.48 \mathrm{mmol}$ of $\mathrm{Fe}^{3+}$. The total oxidizing capacity of the bed under the tested conditions $\left(C / C_{0}=0.5, \mathrm{~V} / V_{0}=420\right)$ was $1.78 \mathrm{mmol}$ of $\mathrm{Fe}^{2+} \mathrm{g}^{-1}$, which constituted ca. $54 \%$ of its theoretical oxidizing capacity. The column process under discussion was accomplished with a high flow rate as for the process of a redox nature. Redox reaction ran considerably slower than the ionic reaction. The slowdown of the flow of the solution through the bed would allow the use of the oxidizing capacity to a higher degree.

\section{Conclusions}

It has been demonstrated that the macroporous S/DVB copolymer containing $N$ bromosulphonamide functional groups in acidic media reacts as an oxidant in two ways. When the $\mathrm{pH}$ of the reaction media is below 3.0, functional groups lose bromine, which, in the reaction media, as a low molecular weight oxidant, oxidizes reducing agents present in it. Such a method of operation can be useful in processes accomplished by batches, when a powerful, heterogeneous oxidant is required; on the other hand, it is unfit for use in the column process. When the $\mathrm{pH}$ of reaction media is above 3.0, bromine is bound with functional groups permanently; it reacts gradually, as the solution of the reductant is supplied onto the column. It has been demonstrated that in the $N$-bromosulphonamide copolymer functional groups can appear in the hydrogen form permanently, which is not the case of the low molecular weight derivative since the free $N$-bromo- $p$-toluenesulphonamide acid is not separable from the aqueous solution. Thus, high molecular weight compounds can yield products exceeding with their structure low molecular weight compounds.

In the next work we will describe the main properties of a new polymeric reagent with $\mathrm{N}$-bromosulphonamide functional groups in $\mathrm{H}^{+}$form. We will compare IR spectra and DTG/DTA charts of the copolymers with $-\mathrm{SO}_{2} \mathrm{NBrNa}$ and $-\mathrm{SO}_{2} \mathrm{NBrH}$ functional groups.

Open Access This article is distributed under the terms of the Creative Commons Attribution 4.0 International License (http://creativecommons.org/licenses/by/4.0/), which permits unrestricted use, distribution, and reproduction in any medium, provided you give appropriate credit to the original author(s) and the source, provide a link to the Creative Commons license, and indicate if changes were made.

\section{References}

1. Fuchs PL (2013) Handbook of reagents for organic synthesis: catalytic oxidation reagents. John Wiley \& Sons Ltd., West Sussex. ISBN 978-1-118-70484-4

2. Nair CGR, Lalithakumari R, Senan PI (1978) Bromamine-T as a new oxidimetric titrant. Talanta 25:525-527. doi:10.1016/0039-9140(78)80089-7 
3. Banerji KK (1987) Kinetics and mechanism of the oxidation of aliphatic aldehydes by sodium $N$ bromoarylsulphonamides in acid solution. Tetrahedron 43:5949-5954. doi:10.1016/S00404020(01)87800-5

4. Singh B, Chand R (1985) Kinetics and mechanism of bromamine-T oxidation of some cyclic ketones in acidic media. Tetrahedron 41:2871-2873. doi:10.1016/S0040-4020(01)96607-4

5. Kumar CHV, Shivananda KN, Jagadeesh RV, Raju CN (2009) Ruthenium complex catalyzed oxidative conversion of aliphatic amines to carboxylic acids using bromamine-T: kinetic and mechanistic study. J Mol Catal A Chem 311:23-28. doi:10.1016/j.molcata.2009.05.025

6. Rangaraju PR, Venkatesha TV, Ramachandrappa R (2014) Kinetic and mechanistic investigation on oxidation of Levamisole hydrochloride by Bromamine-T in hydrochloric acid medium. IOSR J Appl Chem 7:30-37

7. Chandrashekar Venkatesha BM, Ananda S, Made Gowda NM (2013) Kinetic and mechanistic study of oxidation of Piperazines by Bromamine-T in acidic medium. Mod Res Catal 2:157-163. doi:10. 4236/mrc.2013.24021

8. Ramachandrappa R, Diwya Iyengar P (2012) Kinetic and mechanistic studies on the oxidation of Voglibose by Bromamine-T in $\mathrm{HCl}$ medium. Res J Pharm Biol Chem Sci 3:835-846

9. Puttaswamy Sukhdev A (2012) Kinetic and mechanistic studies of oxidation of an antiallergic drug with Bromamine-T in acid and alkaline media. Bull Korean Chem Soc 33:3544-3550. doi:10.5012/ bkcs.2012.33.11.3544

10. Rangaraju PR, Venkatesha TV, Ramachandrappa R (2012) Kinetics and mechanistic investigation on oxidation of Cetirizine dihydrochloride (CTZ) by Bromamine-T (BAT) in HCl Medium. Res J Pharm Biol Chem Sci 3:432-442

11. Puttaswamy Jagadeesh RV, Made Gowda NM (2005) Oxidation of metronidazole with sodium $N$ bromo- $p$-toluenesulfonamide in acid and alkaline media: a kinetic and mechanistic study. Int J Chem Kinet 37:700-709. doi:10.1002/kin.20118

12. Vyas R, Chanda BM, Bedekar AV (1998) Bromamine-T: a superior source of nitrene for aziridination of olefins. Tetrahedron Lett 39:4715-4716. doi:10.1016/S0040-4039(98)00864-8

13. Chanda BM, Vyas R, Landge SS (2004) Synthesis of aziridines using new catalytic systems with bromamine-T as the nitrene source. J Mol Catal A Chem 223:57-60. doi:10.1016/j.molcata.2003.09. 039

14. Kolvari E, Ghorbani-Choghamarani A, Salehi P, Shirini F, Zolfigol MA (2007) Application of $N$-halo reagents in organic synthesis. J Iran Chem Soc 4:126-174. doi:10.1002/chin.200742256

15. Sharma CM, Kashyap B, Phukan P (2014) Aziridination of olefins with bromamine-T in presence of iodine as catalyst. Indian J Chem B 53:750-753

16. Bogoczek R, Kociołek-Balawejder E (1991) N-Bromo-poly(styrene-co-divinylbenzene)sulphonamide metal salts. Angew Makromol Chem 188:85-96. doi:10.1002/apmc.1991.051880108

17. Kociołek-Balawejder E (1997) Redox copolymer with $N$-bromosulfonamide groups for the decomposition of cyanide ions in dilute aqueous solutions. Angew Makromol Chem 251:117-130. doi:10. 1002/apmc.1997.052510111

18. Kociołek-Balawejder E (1999) A redox copolymer containing active bromine as oxidant for thiocyanates. Angew Makromol Chem 268:46-51. doi:10.1002/(SICI)1522-9505(19990701)268:1<46: AID-APMC46 $>3.0 . \mathrm{CO} ; 2-\mathrm{Z}$

19. Kociołek-Balawejder E (2002) A crosslinked copolymer with $N$-bromosulfonamide pendant groups as oxidant for residual sulfides in alkaline media. Macromol Mater Eng 287:604-610. doi:10.1002/ 1439-2054(20020901)287:9<604:AID-MAME604>3.0.CO;2-D

20. Ociński D, Stanisławska E, Kociołek-Balawejder E (2013) Oxidation of arsenite in aqueous solution by redox copolymer with $N$-bromosulfonamide functional groups. React Funct Polym 73:108-113. doi:10.1016/j.reactfunctpolym.2012.08.010

21. Kociołek-Balawejder E (2002) A copolymer with $N$-chlorosulfonamide pendant groups as oxidant for residual sulfides. React Funct Polym 52:89-97. doi:10.1016/S1381-5148(02)00084-6

22. Bogoczek R, Kociołek-Balawejder E, Stanisławska E (2008) Potentiometric studies of oxidationreduction reactions with redox copolymers. J Appl Polym Sci 107:2190-2195. doi:10.1002/app. 27244

23. Bogoczek R, Kociołek-Balawejder E, Stanisławska E, Żabska A (2007) Using macroporous $N$ chlorosulfonamide S/DVB copolymer as an aid to iron removal from water. Pure Appl Chem 79:1491-1503. doi:10.1351/pac200779091491 